\title{
Imaginarios sociales de la prostitución y la trata sexual: transferencias en la invisibilidad
} Social imaginaries of prostitution and sexual trafficking: transfers in invisibility

Silvia Pérez Freire

Recibido: 02/10/2017

Aceptado: 16/04/2018

\section{RESUMEN}

En este artículo se presenta un avance de los resultados obtenidos de la investigación realizada sobre los imaginarios sociales de la prostitución y la trata sexual en los denominados observadores/as de primer orden: esto es, personas con una relación directa con ambas realidades y que, desde la perspectiva de pertenencia a diversos sistemas sociales, ofrecen unas particulares vivencias, prácticas sociales y discursos que revelan las transferencias existentes entre ambas. La parte que avanzamos es la que pertenece al clientelismo sexual y las mujeres víctimas $(n=24)$. Se constata a través de grupo de discusión y entrevistas en profundidad cómo la legitimación social de la prostitución ocasiona la invisibilización de la trata sexual, que se constituye como un mecanismo de ocultación de la propia prostitución para no ser interpelada social ni jurídicamente aspirando a convertirse en el fenómeno opaco en esta problemática.

Palabras clave: imaginarios sociales, prostitución, trata sexual, observación de primer orden, sistemas sociales.

\begin{abstract}
This article presents an advance of the results obtained from the investigation on the social imaginaries of prostitution and sexual trafficking in the so-called first-order observers: that is, people with a direct relationship with both realities and, from the perspective of belonging to diverse social systems, they offer individual experiences, social practices and speeches that reveal the existing transfers between both. The part that we advance is the one that belongs to the sexual patronage and the women victims $(n=24)$. Through a discussion group and interviews in depth, it emerges how the social legitimacy of prostitution causes the invisibilization of sexual trafficking, which is constituted as a mechanism to conceal the prostitution itself so as not to be socially or legally questioned, becoming the opaque phenomenon in this issue.
\end{abstract}

Silvia Pérez Freire es doctora en Sociología, consultora científica y de proyectos sociales para universidades, administraciones públicas y tercer sector. Coordinó los programas de personas en situación de prostitución de la Asociación feminista Alecrín. Es cofundadora de la Red Gallega contra la Trata Sexual. Correo electrónico: silviaperezfreire1@gmail.com. ID: https://orcid.org/0000-0003-4224-8381

Cómo citar este artículo: Pérez Freire, S. (2018). Imaginarios sociales de la prostitución y la trata sexual: transferencias en la invisibilidad. Atlánticas. Revista Internacional de Estudios Feministas, 3 (1), $62-84$ doi: http:/ /dx.doi.org/10.17979/arief.2018.3.1.3080 
Keywords: social imaginaries, prostitution, sexual trafficking, first-order observation, social systems. 


\section{INTRODUCCIÓN}

La prostitución y su "continuum": la explotación sexual y la trata sexual son tres contextos que confluyen y se manifiestan en el sistema prostitucional como si de un círculo vicioso se tratase $\mathrm{y}$, aunque podamos discernir distinciones jurídicas entre ellos, lo cierto es que social e individualmente se encuentran concatenados, simultaneados y en total sincronía. De este modo, es habitual encontrarse con mujeres que han transitado en diferentes momentos de su vida por estas situaciones y aunque este hecho pareciera no tener mucha importancia y se percibe como un suceso improbable y/o contradictorio lo cierto es que nos revela que nos encontramos ante otro círculo de violencia de género. Uno no muy distinto al que sufren las mujeres víctimas de violencia en el ámbito de la pareja afectiva y que, como éste, también conduce a una asimilación y adaptación a diferentes manifestaciones de violencia machista. En estos contextos, sin embargo, los agresores son diversos y múltiples y la mujer no cuenta con la solidaridad social ni particular de la primera. Esta falta de empatía social parte de preceptos imaginados constituidos para los que la única situación reconocida de forma segura es la de prostitución. La explotación sexual y, sobre todo, la trata es discutida constantemente (también por parte de los operadores agentes encargados de detectarla y/o identificarla) y el largo y tedioso proceso de reconocimiento institucional (sólo es víctima la tratada) devuelve a la mujer a una situación de partida de extrema vulnerabilidad (Pérez Freire, 2013).

¿Cómo es posible que alguien que haya sido tratado sexualmente, incluso bajo duros abusos físicos y secuestro, permanezca en situación de prostitución y/o explotación sexual una vez superada la coacción de sus tratantes? La realidad nos muestra que nos encontramos con mujeres para las que la violación de sus derechos fundamentales a través de la trata sexual se les presenta como algo irremediable y/o admisible. Paradójicamente, en este proceso de asimilación y/ o círculo en el que se ve envuelta la mujer acaba legitimando al propio sistema prostitucional naturalizando en algunas mujeres (disposición de género y raza) su ethos prostitutivo". La máxima del teorema de Thomas mediante la cual "si las personas definen una situación como real, ésta será real en sus

\footnotetext{
${ }^{1}$ Este hecho queda ejemplificado en las declaraciones realizadas por un dueño de un club de alterne en el estudio de prostitución realizado en la ciudad de Lugo: el racismo y el machismo existente en la consideración de las mujeres extranjeras, especialmente latinas, que son percibidas como "las naturalizadas" para esta actividad: "duro lo puede decir que lo sea para una mujer española pero una mujer latina no lo puede decir... el sexo para esta gente es un deporte... ¿que (otro) trabajo le vas a exigir si no saben hacer nada?". (Alecrin, Pérez Freire y Carracedo, 2006: 55).
} 
consecuencias" (Thomas, 1929: 572) adquiere tintes dramáticos para las víctimas de trata: se impone la necesidad de adaptarse a un destino que se les presenta como inexorable y falsamente inocuo (desde la trata, en primer lugar, a la explotación sexual y/o a la prostitución, más tarde). En ese camino, los clientesputeros transitan con una total ausencia de corresponsabilidad en estos estadios desplegando su práctica social sin contradicciones aparentes (Gómez, Pérez y Verdugo, 2015). En este artículo se presentan parte de los resultados realizados en la investigación "Victimización en la trata sexual: imaginarios e invisibilización" que aglutina el trabajo realizado desde el año 2011 hasta el 2016 en esta materia ${ }^{2}$. Los imaginarios sociales se configuran como la herramienta que nos va a permitir comprender las contradicciones y el enmarañamiento existente en un fenómeno tan difuso, opaco y divergente como es la prostitución en sus múltiples manifestaciones.

\section{SITUANDO LA PROSTITUCIÓN EN EL MUNDO Y EN EL SISTEMA SEXO-GENERO}

Las relaciones de género, entre las personas y grupos organizados, forman una de las estructuras principales de las sociedades y el impacto que los movimientos sociales, principalmente feministas, han tenido en esta cuestión, ha trastocado el orden social establecido (Connell, 2003). El género se constituye como un conjunto de ideas, representaciones, prácticas y prescripciones sociales que una cultura desarrolla desde la diferencia anatómica entre mujeres y hombres, para simbolizar y construir lo masculino y lo femenino (Lamas, 2000). La construcción de la identidad social masculina se relaciona con el sistema sexo-género de una sociedad (Otegui, 1999). Este sistema estaría basado en diferentes explicaciones teóricas sobre la masculinidad que podríamos sintetizar en: de tipo esencialista, por un lado, con una naturalización de las características socialmente construídas (Goldberg, 1973; Chodorow, 1989; Gilligan, 1982; Moore y Gillette, 1993), de tipo funcionalista, que legitiman el mantenimiento del orden socio-sexual hegemónic.o en las sociedades (Parsons, 1999; Gilmore, 1990) o de tipo diverso en el que el componente relacional crea procesos hegemónicos socio-históricos específicos de poder y que se materializarían en las teorías constructuvistas (Bourdieu, 2000; Connel, 2003) y las teorías queer (Butler, 2001). Con los estudios de género se analizan las

\footnotetext{
${ }^{2}$ Investigación que dió como resultado la tesis doctoral titulada de igual forma en los Estudios sobre juventud y sociedad del departamento de Sociología de la Universidad de Santiago de Compostela dirigida por Juan Luis Pintos de Cea-Naharro y David Casado Neira.
} 
relaciones asimétricas de poder y oportunidad que tienen lugar en la sociedad en consonancia con el cuerpo sexual (Ortner, 1979) y la prostitución está jugando un papel clave en este sentido en la actualidad. Por otra parte, la industria sexual actualmente es un fenómeno generizado, es decir, atravesado por el género en donde los sexos no poseen el mismo papel (Pateman, 1988) y desde esta perspectiva debe ser analizado. Se trata, además de una institución histórica (García Massagué, 2009), que cambia al mismo tiempo que lo hace las propias sociedades y que se adapta para ser funcional a otros sistemas, como puede ser el patriarcal y el neoliberal (Gimeno, 2012). Se ha pasado, en los años 60 y 70, de pronosticar que la prostitución, fenómeno considerado residual y analizado durante dos siglos como el modelo mismo de la subordinación femenina (Millet, 2010), desaparecería con el avance de la igualdad femenina y la liberación sexual, a un mercado actual enormemente industrializado (Jeffreys, 2011), globalizado, con un gran auge en beneficios económicos y en el que en nombre de la libertad sexual se reconstruye la prostitución como un trabajo pseudolegítimo y/o sacrifical para algunas mujeres que funcionan como base de la propia industria del sexo (Casado-Neira y Pérez Freire, 2015). ¿Qué ha pasado en este camino? En un contexto socioeconómico en donde se acrecienta la percepción de falta de garantías en el acceso a la justicia, a la igualdad de oportunidades y al derecho a no sufrir discriminación (AI, 2009; CEDAW, 2014) ¿qué papel está jugando la prostitución? Saskia Sassen (2003) la sitúa dentro del núcleo duro de las denominadas nuevas clases de servidumbres, entre otras muchas, a las que nos ha conducido la nueva economía capitalista y sus políticas neoliberales. Las mujeres migrantes con necesidades económicas extremas y que buscan mejorar su situación constituyen la mayoría de la población dedicada a esta actividad (dentro de éstas, las que se encuentren en situación irregular, que tendrían menos alternativas). Por todo ello, aunque se sigue empleando la palabra prostitución para definir las dinámicas de relaciones sexuales comerciales, se nombra cada vez más la necesidad de hablar de industria sexual para definir una situación que se adapta y se desarrolla con las claves del mercado (Cobo, 2017). La gran variedad de modalidades de intercambio sexual pagado según los espacios, las nuevas tecnologías de la comunicación (internet), tipos de contactos, dinámicas relacionales, etc hasta ahora conocidas se han diversificado enormemente y están permeando otros ámbitos (trabajos de hostelería y alquileres que incluyen la obligación de ofrecer sexo de pago ocasional, por ejemplo). Con el proceso de globalización la dimensión que ha adquirido la prostitución en las últimas 
décadas está directamente relacionada con su enorme capacidad de generar cuantiosos ingresos económicos para un gran contingente de personas y especialmente, para los estados. Se conoce que para China representa el $8 \%$ de la economía y un 5\% de PBI para Holanda (Daley, 2001) y el caso de los países del sudeste asiático es mucho más relevante pero las estimaciones son menos precisas por la ausencia de registros fiables dado que el sector se encuentra totalmente diversificado (implica a empresas de casi todos los sectores: desde agencia de viajes, restauración, transportes, etc) y así se reflejó en su día en un informe elaborado por la OIT para los países Filipinas, Indonesia, Tailandia, Malasia en donde se estimaba que solamente el sector del comercio sexual directo suponía ya entre un $2 \%$ y un $14 \%$ de su PIB (Lim, 1998). El turismo sexual ha provocado una mundialización de esta industria como una expresión de dominación de los países del Norte sobre los países del Sur o del Este. Es, según Michel (2006) un reflejo de una ideología de la neocolonización, una especie de tragedia silenciosa que refleja un totalismo tranquilo sobre un fondo de democracias corrompidas por un capitalismo salvaje y que se caracteriza por el encuentro entre la miseria afectiva y sexual del Norte con la miseria económica del Sur o del Este. Esta sólida interrelación entre la prostitución y otras grandes industrias e infraestructuras, también ha generado que en algunos países el ejército sostuviera el sistema prostibulario a gran escala, como los Estados Unidos y Japón, en las décadas de los años treinta y cuarenta. En casos como Corea, Filipinas y Tailandia la precisión industrial con la que los estados garantizaban a sus soldados de prostitución parece estar vinculado a su gran desarrollo actual, ahora más orientado para los turistas (Jeffreys, 2011).

Históricamente, los tratados internacionales han establecido en origen una lucha clara contra la prostitución, en cada una de sus expresiones (tanto la explotación sexual como la trata) siendo considerada una manifestación de violencia de género y desigualdad social. Esto ha cambiado y este enfoque sólo se mantiene exclusivamente con la trata de personas, antes denominada trata de mujeres y ésta, diluida en la actualidad también, con otras formas de explotación (OHCHR, 2002; NU, 1950; NU, 1979; NU, 2004). Estos hechos históricos han variado no sólo la dimensión del propio fenómeno sino sus dinámicas internas de funcionamiento $\mathrm{y}$, consecuentemente, también de su legitimación social. ¿Cómo? Un elemento palpable es el uso del lenguaje. En las últimas dos-tres décadas la normativa política ha ido transformándose a la par que la prostitución se ha normalizado y globalizado. Esto ha significado 
invisibilizar una determinada terminología y destacar otra. De este modo, el término prostitución se ha convertido en un concepto cada vez menos utilizado y se ha pasado a mencionar otros como relación sexual comercial o, según los casos, trabajo sexual. Esto sucede incluso sin existir una línea política y/o ideológica definida. Lo mismo se produce con los denominados clientes sexuales (asimilando su consumo como un producto más) y trabajadora sexual (en vez, de prostituta o prostituída) y, por último, industria sexual (Jeness, 1993; Sullivan, 2007). Así, este mercado ligado al del espectáculo se configura imaginariamente para muchas mujeres como una estrategia de desarrollo y las remesas de dinero se han convertido en herramientas de los gobiernos pobres para amortiguar el desempleo y la deuda externa. Ambas estrategias tienen cierto grado de institucionalización de lo que dependen cada vez más algunos gobiernos y tanto el Fondo Monetario Internacional como el Banco Mundial instan a los países pobres endeudados que desarrollen una industria del ocio y del espectáculo que haga posible el pago de esa deuda (Cobo, 2014). El caso de España ha sido peculiar ya que ha respondido de forma muy tardía a las exigencias del derecho internacional en el tratamiento normativo que debía aplicarse a la trata sexual y este hecho podría estar asociado a la alta tasa de consumo de prostitución por parte de los varones españoles, sin un perfil aparente (CIS, 2009) aunque ligado a un mismo modelo de masculinidad hegemónica (Ranea, 2016). Esta tolerancia social con los puteros permea la visión de la propia prostitución y, por supuesto, de la trata sexual. Los vaivenes jurídicos entorno a la explotación sexual es una expresión más de ello y así, la intermediación lucrativa directa de la prostitución ajena aunque penada está tolerada y por lo tanto, ni se persigue ni se castiga. La amplia normalización de la prostitución (no está reconocida como actividad laboral propia pero se utiliza el subterfugio del alterne y otros) ha desembocado en un desarrollo del mercado sexual nacional inusitado (Ropero y Ruiloba, 2012; Fernández Olalla, 2015). Esta situación hace posible que actualmente podamos hablar de un fortalecimiento del sistema prostitucional basado en tres claves: la primera, la dominación masculina generadora de impunidad y connivencia social (despliegue en la relación sexual pagada de un tipo de masculinidad hegemónica articulada bajo la misoginia, el androcentrismo y la heteronormativad); la segunda, la existencia de una corrupción generalizada de las instituciones (sobre todo, política y policial) que no afronta el fenómeno con la seriedad y rigurosidad debida; la tercera, la transferencia de responsabilidades y de victimización: la oferta pasa a ser la que genera la 
demanda y por lo tanto, son las mujeres las que edifican la institucionalización de la prostitución y los puteros, víctimas de su condición de hombres.

\section{CONSIDERACIONES TEÓRICAS Y METODOLÓGICAS}

En la investigación realizada y que avanzamos en este artículo, analizamos las narraciones de hombres puteros, principalmente, y de mujeres víctimas de trata sexual y otros delitos concatenados empleando la teoría de los imaginarios sociales. Esta teoría es una forma de comprender los fenómenos sociales en donde el marco de interpretación sociológica opera mediante dos mecanismos: el denominado constructivismo sistémico (Luhmann, 1998, 2006) y el metacódigo relevancia-opacidad (Pintos, 2003). Con el primero se distribuye y se acopla la sociedad y con el segundo se descifra lo que subyace en la práctica social de sus miembros, esto es, el denominado trasfondo de significación. Con ello, trataremos de entender por qué se actúa de una manera y no de otra (o, por qué la gente se cree unos cuentos y no otros). Las características de los sistemas ofrecen una perspectiva de observación mediante la cual se valora lo que sucede de una determinada manera (incluyendo y excluyendo determinados elementos) implicando con ello al conjunto de sus miembros. Para determinar estos planos de la realidad social se realiza un análisis basado en tres dimensiones: lo que dicen (discurso), hacen (práctica social) y cuentan (vivencias) las personas implicadas.

Figura 1. Triángulo analítico aplicado a los imaginarios sociales

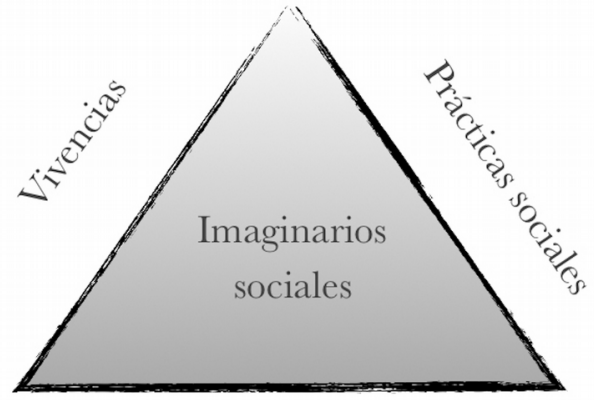

Discursos

Dado que los imaginarios sociales “están siendo esquemas construidos socialmente, que orientan nuestra percepción, permiten nuestra explicación y hacen posible nuestra intervención en lo que en diferentes sistemas sociales sea tenido como realidad" (Pintos, 2014:7-8), se trataría de realizar un análisis 
comparativo de las diferentes cosmovisiones respecto de la prostitución y la trata sexual en cada uno de los grupos/sistemas estudiados hallando las distinciones que permiten otorgar relevancias a algunos datos (lo que expresa sólo un grupo) y opacidad a otros (lo que expresan todos menos alguno). Este contraste desvela y hace emerger los imaginarios sociales, las prescripciones sobreentendidas por las que operan los sistemas y las personas. La comparativa va más allá de las categorizaciones cualitativas de los campos semánticos más utilizados por los/as participantes (aunque se tienen en cuenta). En la narración, la expresión del triángulo analítico aplicado a los imaginarios sociales se traduciría en: qué se nombra (lexemas con valor de sentido), cuál es el significado de la secuencia (hecho narrado) y la experiencia sentida (recuerdo rememorado). En la investigación realizada han participado 67 informantes mediante entrevistas en profundidad y grupos de discusión agrupados en los siguientes sistemas: responsables municipales $(n=3)$; Ong's de acreditada experiencia $(n=20)$; fuerzas y cuerpos de seguridad (policías y guardia civiles), judicial y de inspección de trabajo $(n=16)$; expertas en la temática desde diferentes disciplinas $(n=4)$; clientelismo sexual y trabajadores/as $(n=12)$ y mujeres víctimas $(n=12)$. A continuación expondremos únicamente las cosmovisiones de los dos últimos (sus perfiles son diversos y heterogéneos siguiendo unos criterios de representación socioestructural).

Tabla 1. Identificación de entrevistas/grupos de discusión utilizados.

\begin{tabular}{|c|c|c|c|c|}
\hline \multicolumn{2}{|c|}{ Mujeres víctimas de... } & Técnica & Recogida & $\mathrm{n}$ \\
\hline $\mathrm{VT}$ & Trata y explotación sexual. Mujer de & Entrevis & Grabación & 1 \\
\hline 1 & $\begin{array}{l}\text { Paraguay, } 23 \text { años, soltera, sin hijo/as. } \\
\text { Denuncia: si }\end{array}$ & ta ind. & $36 \mathrm{~m}: 33 \mathrm{~s}$ & \\
\hline VT & Trata y explotación sexual. Mujer de & Entrevis & Grabación & 1 \\
\hline 2 & Brasil, 32 años, soltera, sin hijos/as. D.: si & ta ind. & 59m:52sfl & \\
\hline VT & Trata y explotación sexual. Mujer de & Entrevis & Grabación & 1 \\
\hline 3 & Brasil, 30 años, pareja de hecho, 3 & ta ind. & $31 \mathrm{~m}: 38 \mathrm{~s}$ & \\
\hline VT & Trata/tráfico y explotación sexual. Mujer & Entrevis & Grabación & 1 \\
\hline 4 & de República Dominicana, 34 años, & ta ind. & $35 \mathrm{~m}: 30 \mathrm{~s}$ & \\
\hline VT & $\begin{array}{l}\text { soltera, } 5 \text { hijos/as. D.: no. } \\
\text { Trata/tráfico v explotación sexual. Muier }\end{array}$ & Entrevis & Grabación & 1 \\
\hline 5 & $\begin{array}{l}\text { de República Dominicana, } 30 \text { años, } 3 \\
\text { hijos/as. D.: no. }\end{array}$ & ta ind. & $27 \mathrm{~m}: 34 \mathrm{~s}$ & \\
\hline VT & Trata y explotación sexual. Mujer de & Entrevis & Grabación & 1 \\
\hline
\end{tabular}




\begin{tabular}{|c|c|c|c|c|}
\hline 6 & Brasil, 34 años, soltera, 2 hijos/as. D.: no. & ta ind & 11m:36s. & \\
\hline VT & Tráfico y explotación sexual. Mujer de & Entrevis & Grabación & 1 \\
\hline 7 & $\begin{array}{l}\text { República Dominicana, } 42 \text { años, viúda, } 2 \\
\text { hijos/as. D.: no. }\end{array}$ & ta ind. & $18 \mathrm{~m}: 00 \mathrm{~s}$ & \\
\hline VT & Trata y explotación sexual.Mujer de & Entrevis & Grabación & 1 \\
\hline 8 & Paraguay, 28 años, soltera, sin hijo/as. & ta ind. & 40m:07s & \\
\hline & D.: si. & & & \\
\hline VT & Trata y explotación sexual.Mujer de & Entrevis & Grabación & 1 \\
\hline 3 & Brasil, 23 años, soltera, 2 hijas. D.: no. & ta ind. & $26 \mathrm{~m}: 28 \mathrm{~s}$ & \\
\hline VT & Trata y explotación sexual. Mujer de & Entrevis & Grabación & 1 \\
\hline 10 & Paraguay, 27 años, soltera, sin hijos/as. & ta ind. & $23 \mathrm{~m}: 27 \mathrm{~s}$ & \\
\hline & D.: no. & & & \\
\hline VT & Prostitución coactiva. Mujer de & Entrevis & Grabación & 1 \\
\hline 11 & Rumanía, 19 años, sin hijos/as. D.: si. & ta ind. & $42 \mathrm{~m}: 27 \mathrm{~s}$ & \\
\hline VT & Trata y explotación sexual. Mujer de & Entrevis & Grabación & 1 \\
\hline 12 & Colombia, de 37 años, 3 hijo/as. D.: no & ta ind. & $17 \mathrm{~m}: 58 \mathrm{~s}$ & \\
\hline
\end{tabular}

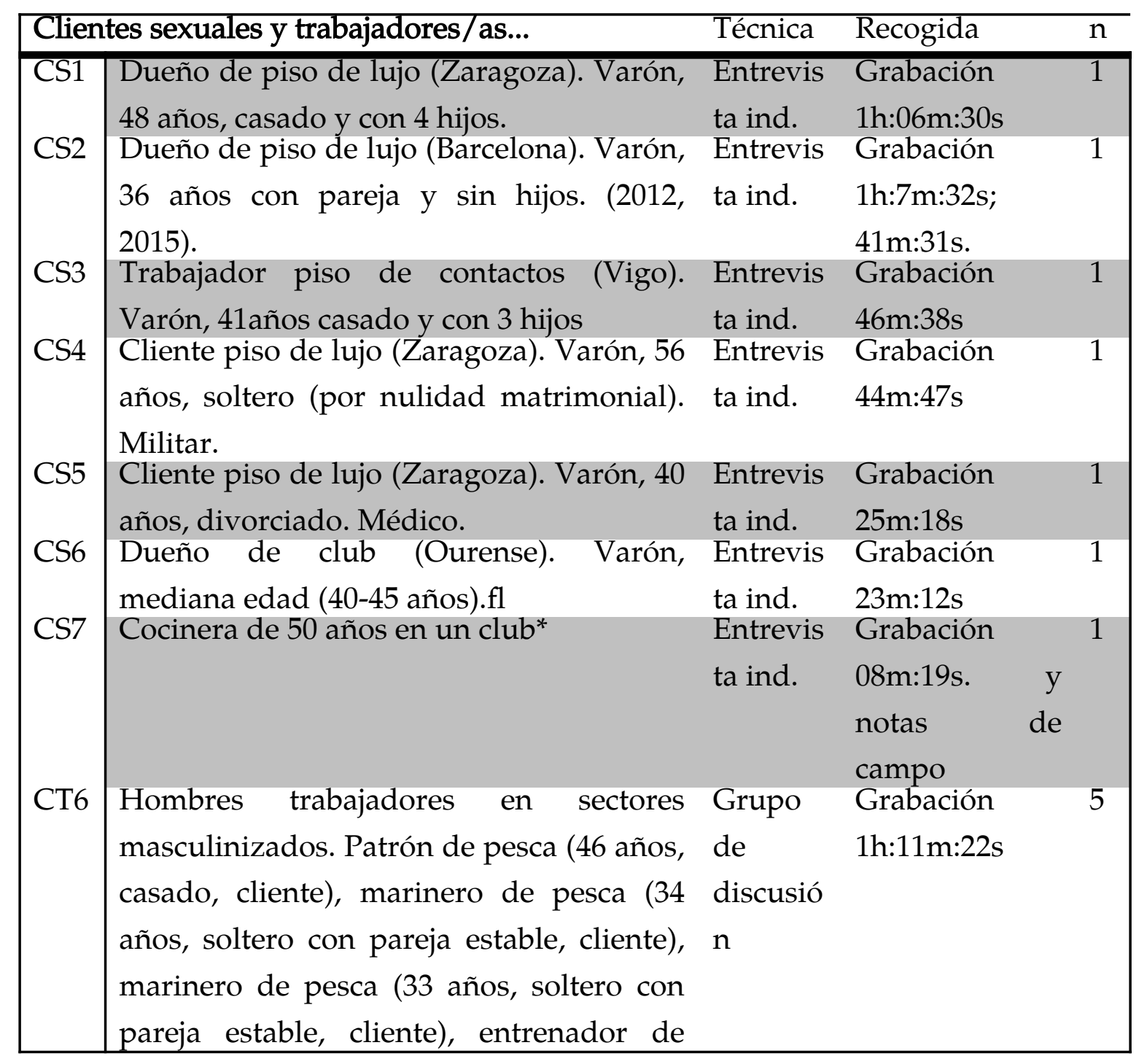




\begin{tabular}{|l|l|}
\hline fútbol (28 años, soltero sin pareja estable, \\
no se manifiesta), entrenador de fútbol \\
$(24$ años, soltero sin pareja estable, no se \\
manifiesta).
\end{tabular}

En el caso de las mujeres víctimas nos encontramos con situaciones de trata sexual de partida que luego derivan en explotación sexual (10 de 12) y dos casos en donde la situación es de tráfico con explotación sexual y prostitución coactiva. En contraposición, las experiencias de hombres-puteros en diferentes contextos de sexo de pago que no se pueden identificar porque no establecen ninguna distinción: todo es prostitución, sin más (algunos también son dueños de clubs, pisos y trabajadores en los espacios prostibularios). Se añade un grupo de discusión de hombres de sectores masculinizados que hablan de su experiencia como puteros y las vivencias de una mujer cocinera trabajadora de un club de alterne).

\section{PROCESOS DE DISOCIACIÓN: ELLAS PARA SOBREVIVIR, ELLOS PARA DISFRUTAR.}

Para legitimar las actuaciones de los sistemas y las personas tiene lugar un proceso social que hace posible su funcionalidad a pesar de las aparentes contradicciones. Este proceso se encuentra definido según el nivel de implicación de los participantes. Se trata de lo que se denomina el magma ${ }^{3}$ social que unifica las disfunciones del propio sistema y que explicaría sus paradojas (Castoriadis, 1989). En el caso tanto de las víctimas como de los puteros, este magma se produce gracias a otro proceso individual que se podría denominar disociación de la realidad: una ejercida para adaptarse al daño personal indeseado de mantener relaciones sexuales íntimas con extraños (separación emocional de su yo corpóreo) y otra, exorcizando el remordimiento inconfesable por estar utilizando sexualmente a una mujer para conseguir el propio placer al margen de ésta. El estigma de puta y su condición de otredad ligada a la apropiación del cuerpo (Segato, 2016) le sirve al putero de coartada para no cuestionarse éticamente la acción parapetando así el objetivo de obtener placer sexual desligado de lo que podría constituirse como un acto violento. De este modo, se anula la empatía y el reconocimiento de cualquier situación que

\footnotetext{
${ }^{3}$ Expresión acuñada por Cornelius Castoriadis, uno de los autores más influyentes en el estudio de los imaginarios sociales. El magma social sería el conjunto de significaciones imaginarias de una institución social que legitima tanto a los individuos como los productos de ésta y que dotan de sentido a las cosas,
} delimitando un umbral de visibilidad. En sus contradicciones reside también su fuerza. 
pudiera entorpecer la consecución de su finalidad (por ejemplo, conocer las condiciones de explotación, existencia de trata, etc.).

\subsection{Cuerpos expropiados}

La disociación se hace imprescindible personal y socialmente para que el proceso de adaptación de las mujeres víctimas sea efectivo y además, resulte ejemplarizante. Se constituye como una estrategia de supervivencia individual que genera un doble impacto social conveniente en el sistema prostitucional: se refuerza y legitima por la propia víctima. Ambos tienen funciones estabilizadoras pero entrañan pugnas internas: en ocasiones, se producen inadaptaciones y algunas de ellas lo representarían las que, finalmente, denuncian (4 de ellas). Las demás, pasan a ser víctimas invisibles para el sistema y a sobrevivir en otros contextos prostibularios, una vez vencida su deuda. Su victimización continúa pero será más improbable que se detecte.

"yo no sabía de que iba a trabajar, yo vine enganada, no lo sabía y yo llegué aquí y me enteré que iba a trabajar siendo prostituta... [...] yo tuve que prostituir, trabajar duro en club y pisos o lo que sea para poder pagar" [VT3: mujer brasileña de 30 años, 3 hijos, situación de trata y explotación sexual. Sin denuncia].

“... y habló... pero tú no vales para limpiar, tú vales para ser puta, habló así para mi. Pero yo vine para limpiar la casa!, el establecimiento, no? no tengo nada en contra, a mi que cada uno haga lo que quiera con su vida pero yo vine para limpiar, no? [...] pero yo nunca trabajé en esto! y... te arreglas que tal hora hay que estar en el salón, vino una chica y... tienes que trabajar (susurrando) si él dice que tienes que trabajar, tranquila que la gente te va ayudar". Traduccción propia del brasileño. [VT2: mujer brasileña de 32 años, sin hijos. Trata y explotación sexual. Con denuncia].

Es posible, además, que a la trata se le sume el tráfico (traslado ilegal de fronteras). En estos casos han sido las rutas: Caribe - Turquía y/o GreciaEspaña donde el viaje suele durar un mínimo de tres meses durante los cuales la explotación sexual se liga al tráfico para continuar el paso de un trayecto a otro (adquiriendo deudas muy altas: 10.000€ en algún caso) sin conocer cuál va a ser realmente todo el recorrido a realizar:

"hay unos viajes que lo hacen que uno tiene que pagar tanto y ahí te resuelven todo [...] ahí tenía uno que buscar a otra gente para poder darle dinero para que cruzara, para cruzar a uno de... de ahí... del ríto que pone ahí de cinco minutos que pone Río Grande: jmil quinientos 
euros! nada más para cruzar, por un monte, sin llegar en avión ni nada porque supuestamente que hay que cruzar la aduana... [...] mucha gente de esas cosas se han abollado y se han ahogado y se han muerto muchísima gente y también de que ellos mismos, lo que tiene la cosa de que le van guiando la... la cosita... los hunden, los hunden... los ahogan... los ahogan cuando van así que llevan mucho peso y que los van tirando...". [VT4: mujer dominicana, 34 años, 5 hijos/as. Trata/tráfico y explotación sexual. Sin denuncia] "yo duré cuatro meses en un país que le llamaban Nicaragua y de ahí me devolvieron, después me mandaron por Grecia y ahí caí presa, nos metieron por el monte [...] yo me metí en eso y me he deseado la muerte y todo eso...[VT5: mujer dominicana, 30 años, 3 hijos/as. Trata/ tráfico y explotación sexual. Sin denuncia]

Una vez en el destino de explotación, comienza un período de resistencia en la que algunas de ellas se niegan a prostituirse. Esto conlleva sufrir encierros, amenazas y coacciones hasta doblegar su voluntad. Las deudas económicas adquiridas inicialmente por un viaje y traslado para la explotación sexual (entre $2.500 €$ y $3.000 €$ ) se pueden saldar entre 3 a 5 meses según los casos en un club en el que la mujer acepta o asimila enseguida su nueva condición de prostituta (durante este tiempo lo habitual es que la mujer no percibe ninguna remuneración). Las que no lo hacen y se resisten unos días (quince-veinte), duplican la cuantía de su deuda al ser trasladadas y/o vendidas a otro club para rentabilizar una explotación que no se ha producido, de momento. Así, las mujeres adquieren nuevas supuestas deudas de 5.000€ a 6.500€ y que tardan en saldar alrededor de un año.

"si porque uno no... escuchar es fácil pero para pasar esas cosas que pasamos es muy... duro, jes muy duro! primero porque teníamos que acostarnos obligadamente con los clientes, con unos viejos, jay, dios! con unos viejos asquerosos queee... que teníamos que estar ahí con los clientes, llorando, llorando... y ellos no les importaba eso, ellos con satisfacerse ahí... no le importaba......] le contamos a un cliente, a un cliente le preguntamos llorando... así, ¿sabes? yo... querían hacer cosas y a mi se me caían las lágrimas y ellos me secaban y seguían haciendo... si." [VT1: mujer paraguaya, 23 años, sin hijos/as. Trata y explotación sexual. Con denuncia].

"me puse enferma a los veinte días y entonces cuando me recuperé tuve que pagarlo todo... allí trabajaba con la regla, todo... daba igual... tenía que meter 
esponja... no!". Traducción propia del brasileño. [VT6: mujer brasileña, 34 años, 2 hijos/a. Trata y explotación sexual. Sin denuncia].

"al llegar nos bajaron a la oficina y cada una porque no todas juntas y nos dijo que teníamos que una deuda de tres mil setecientos euros [...] si y a parte de eso nos pidió el billete de vuelta y el pasaporte y nos dijo que teníamos una deuda que cumplir con ellos" [VT8: mujer paraguaya, 28 años, sin hijos/as. Trata y explotación sexual. Con denuncia].

Durante la permanencia en diferentes espacios (clubs y/o pisos, principalmente), las mujeres pueden ser detenidas al transcurrir los meses de estancia regular (sanción administrativa) sin que su situación de trata sexual sea detectada. En otros casos se entremezclan los contextos: no hay captación pero sí tráfico (cruce ilegal de fronteras) acompañado de explotación sexual y prostitución coactiva.

"estuve un tiempo en el que el club estaba todo cerrado, todo cerrado, no podías salir, abría el club la hora que era para abrir el club y ahí sí ellos te dejaban salir para andar un poco por la playa". Traducción propia del brasileño. [VT9: mujer brasileña, 23 años, 2 hijas. Trata $y$ explotación sexual. Sin denuncia].

"y... a las once o así llegué a la policía y bueno, al principio la policía no me hizo caso porque se pensaba que era una broma o que... pero me ve que cuando empiezo a llorar y le digo que estoy aquí para poner una denuncia, por un delito, porque sé que en España es un delito". [VT11: mujer rumana, 19 años, soltera, sin hijos/as, prostitución coactiva. Con denuncia].

Con el siguiente testimonio se pone de manifiesto el tránsito de las mujeres en situación de prostitución por diferentes grados de explotación. Es relevante comentar que la situación de trata sexual vivida se había desarrollado 10 años atrás y la falta de oportunidades (su situación económica y, sobre todo familiar: sola y con hijos a cargo) la obliga a considerar transcurrido un tiempo volver a ejercer la prostitución en un club para poder afrontar un futuro incierto. Su relato es relevante por dos razones: la primera, porque es habitual encontrarse con mujeres en donde la entrada en nuestro país fue anterior a la tipificación del 
delito de trata por lo que no son ni serán reconocidas como víctimas de trata sexual y la segunda, porque es frecuente que el consentimiento inicial (o el conocimiento de la actividad de destino) no tenga la consideración debida por parte de las autoridades encargadas de identificar la existencia de trata sexual, invisibilizándose nuevamente muchas mujeres en esta situación.

"en Colombia te cogen y teee... tú ya sabes a lo que vienes, yo ya sabía que yo venía a la prostitución pero claro, hace diez años, se veía mucho dinero y entonces te cogen y te dicen: mira, tu vas a ganar muchiiiísimo dinero, en un mes, dos meses vas a tener para comprar una casa, para todo... mmm... claro, tú te ilusionas y te vienes pero tienes que ir y trabajar en un club, así, así, así, asá... bueno, pues yo cogí, lo primero que te piden en Colombia es la dirección de tu familia, jtodo! Porque te amenazan, te amenazan porque te dicen que si tu te vuelas y no pagas en España, el pasaje o cualquier cosa, venimos a por tu familia, jeh! es lo que te dicen, ¡bueno!... y como tú no te vienes con ese pensamiento $y$ te dicen que te van a cobrar... bueno, en ese tiempo, me dijeron a mi que me iban a cobrar tres millones de pesetas o algo así, es que ahorita no lo tengo bien, bueno... jel caso es que a mi me cobraron cuatro veces eso! [...] bueno... de allí, de allí de Bilbao me llevaron a Burgos, a otro club... o sea, me vendieron comooo... [silencio: se emociona]... bueno, allí yo terminé de pagar la deuda [...] en ese tiempo llegaban muchas chicas, ahí... vivíamos en el mismo club también, no te dejaban ver ni un duro, yo... yo... a mi no me dejaban salir, para nada, para nada... bueno, pasó el tiempo...". [VT12: mujer colombiana, 37 años, 3 hijos, trata y explotación sexual. Sin denuncia].

Este círculo de explotación es percibido como una realidad paradójicamente cercana en el tiempo y en el espacio, un club en el que se siente reconocida en las otras mujeres que ejercen aunque no habla ni interacciona con ellas. La existencia de un pacto de silencio tácito por el que se moldea la voluntad y el proceso de asimilación a estos contextos es clave para que el sistema prostitucional aspire a una nueva invisibilización social y se legitime a sí mismo. Igualmente se produce con y entre los prostituidores clientes, que no son interpelados por el estado a través de las leyes con la participación en la comisión delictiva de, al menos, la trata sexual ni por la sociedad, que los ampara y normaliza (la utilización narrativa de los chistes ligados al putero, el puterío y las putas son una expresión socio-lingüística de la banalización de un problema social de primer orden, tal y como sucedía antaño con los malos tratos). 


\subsection{Derechos de la masculinidad}

La cosmovisión del clientelismo sexual sobre el negocio del sexo se podría aglutinar en: la prostitución cumple una función social (como varón es natural ser putero) y por lo tanto los espacios designados para ello son de utilidad pública; la trata sexual es una realidad ajena (de otros lugares, de otra gente) y; la prostituta es una radicalización del tipo de mujer perversa, interesada y fría que engaña y engatusa al hombre para su propio beneficio (es la oferta la que genera la demanda y no al revés). Por un lado, se legitima el derecho de apropiación de los cuerpos de las mujeres por la existencia de la propia institución y, a la vez, se elude cualquier responsabilidad en la práctica social que lo genera (la disociación aquí se produce, por tanto, con el contexto). En sus prácticas, discursos y vivencias se despliega un ethos masculino basado, sobre todo, en la consideración subalterna de la prostituta que necesitan idealizar en la puta viciosa para hacer efectivo su propio placer sexual.

"pues que te desahogas, evidentemente, te desahogas, es un instinto que llevas engendrado ahí, que, que, que en principio era el de la procreación pero ahora en estos días ya no es la procreación, es el placer por el placer pero que esto no es de ahora, de hace dos mil años..." [CS4: Cliente de piso de lujo (Zaragoza), varón, 56 años, soltero (nulidad matrimonial), militar.]

"(se ríe) el consumo, el consumo - impulso, es como... es como, vamos a ver, no me gusta... fijate, lo que ellas son que para mi son muy respetables, no me ha gustao lo que voy a decir el... ningunearlas, ni el degradarlas, ni el burlarme de ellas, ¿no? es como, o sea tú vas, seleccionas un sandwich en una máquina y tienes el sexo con esa... y ya te olvidas, vas servido y no tienes que andar luego con el coqueteo, la copa, las horas, "pa" aquí, "pa" allá, que no sé si a las mujeres os pasa pero bueno, la verdad es que es eso... [CS5: cliente de piso de lujo (Zaragoza), varón, 40 años, divorciado. Médico]

"cada tío tiene un gusto, ¿sabes? yo lo tengo muy claro a veces la más linda es la más frígida, ijoder! no me envenenaré porque sino, ¿sabes lo que te quiero decir? es como la comida, se come más con los ojos que con la polla, ¿sabes? a veces ves y esta es la más guapa, la más cachonda, jbuahhh! y después llegas arriba a la habitación y la tía... al poco ya te dice: jinvítame a una raya! después, esto... sale, así no... que 
me haces daño, estoy aquí, voy al baño...vamos a ver, esta tía me está chuleando el tiempo ijoder! [CS3: cliente-trabajador de un piso de contactos (Vigo), varón, 41 años, casado].

La mujer en situación de prostitución suple lo que es percibido como una necesidad que no se colma con otras relaciones y con la que se obtiene un valor añadido derivado de su complaciencia (que aunque fingida) se teatraliza como una salvaguarda de la hombría. Esta esfera de escenificación se amplifica en la experiencia que nos relata el siguiente testimonio que, sin cuestionarse las condiciones en las que se encuentra la mujer y en las que va tener lugar el encuentro sexual (sin poder hablar el mismo idioma, por ejemplo) se compromete sólo con el hecho de que lo intentaran engañar haciéndole creer que una chica brasileña podía ser china, lo que él solicitara. Además, se hace un ejercicio de cinismo y falso paternalismo en la práctica clientelar: pagando por sexo se está ayudando a las mujeres, principalmente.

"como yo he competido toda mi vida en karate, he sido competidor $y$ tal, siempre había tenido el morbo porque yo había estado en Pekín, he estado en todos los lados del mundo compitiendo, ¿vale? pero siempre había tenido el morbo de... una chica china y digo... [chasquido con los dedos] jbah! me bajo, me voy a conocerla, entonces me fui a conocerla y la conocí en un piso cutre y cuando me refiero a un piso cutre ya no eran las instalaciones del piso que también eran cutres sino en un piso cutre donde la dueña... eran chicas, había solamente creo que eran tres, eran chicas sudamericanas y para dar un morbo diferente al resto de la ciudad les obligaba a disfrazarse de chinas, quiero decir ella misma, ella misma que ella sí que era japonesa, pues las cogía y las hacía como una especie de moño todo el pelo así... recogido arriba, como una china, les metía los palillos, les pintaba los ojos de verde así... pues eso, para intentar caracterizarlas como chinas, ¿vale? [...] O sea, te pagaré y me iré pero me siento engañado, por lo menos quiero irme con la satisfacción de saber de donde eres. Entonces, a base de hablar yo solo porque hablaba yo solo como un gilipollas, porque claro ella con sólo decirme ñiki, ñiki, ñiki, ñiki pues ya está y... al final, yo creo que o en mi mirada o en mi expresión o por lo que fuera, digamos que confió y entonces... no hablaba perfectamente el español porque era brasileña, no hablaba perfectamente el español pero entendía perfectamente y sí 
que se podía comunicar hablando despacito... pero se podía comunicar y entonces se me acercó y me dijo: pues soy brasileña pero me obligan a hacer esto y a mi... digamos que se me revolvió el estómago, se me subieron las bilis porque... humillar a una chica de esa manera, me parece tan cruel, me parece tan asqueroso, ¿entiendes? que cogí y dije: ¡vale! muy bien, digo pues... no sé cómo te puedo ayudar pero te voy a ayudar... [...] Con lo cual, me acosté con ella pero le quité los palillos, le quité... cogí una toalla, la mojé, le quité todo de lo de esto y le dije: eres brasileña y eres brasileña y jvale! he picado y ya estoy aquí y punto pero me voy con la satisfacción de con quién he estado en la cama y que no me la han colado gato por liebre..." [CS1: Dueño-cliente de piso de lujo (Zaragoza), varón, 48 años, casado].

En el caso de los dueños de negocios de prostitución se trata de hombres con una amplia experiencia previa en este terreno (de más de 10 años) y son conocedores de las estrategias que se suelen utilizar para llenar el local de mujeres (la trata sexual es un mecanismo más de captación). Esta visión contrasta con las de los clientes, que comentando el visionado de programas de televisión que narran experiencias de trata, no se reconoce la existencia de tal realidad.

"las rumanas, por ejemplo, que son el 90\% de los macroburdeles, son... vienen, la mayoría de... de tráfico de... trata de blancas, pueden ser voluntarias o no, vienen a través de unas organizaciones ilegales, un club muy grande no puede llenar una plantilla de 200 señoritas siendo sólo simpático, tienen proveedores, no se dice, no se puede decir pero es así, es una realidad..." [CS2: Dueño de piso de lujo (Barcelona), varón, 36 años con pareja].

" bueno pues te engancha porque es una cousa queee, es dicir, en la época atrás, veías un futuro en esto, no? un dueño de un local... [CS6: Dueño de un club de alterne (Ourense), varón, 40-45 años). Traducción propia del gallego.

"veintiún días en un club y se fue a buscar... e hizo la visita con una prostituta de que estaba trabajando para ayudar a su familia, ¿vale? le dio un concepto de que... parece que la prostituta esa estuviera forza... forzada, ¿no? que vino forzada a ejercer la prostitución aquí a España para alimentar a su familia, entonces claro, la puso la lagrimita, ella 
puso la lagrimita... y tal y cual pero a lo mejor, no fue la realidad de eso". [CT6: Grupo de discusión de marineros y jugadores de fútbol. S1: Cliente, 46 años, casado, marinero].

A través de los testimonios de los hombres consumidores de sexo de pago se reafirma una determinada visión de la sexualidad, irrefrenable y esencializada atravesado con el ejercicio de un tipo de masculinidad (virilidad vinculada a mantener cuántas más relaciones sexuales, mejor), lo cual sitúa a la prostitución como una opción más dentro de las posibilidades accesibles para obtener sexo. La falta de empatía de los puteros no sólo contrasta con la experiencia de las mujeres en situación de prostitución, explotación sexual y/o trata sino también con otras mujeres que transitan en su mismo espacio. En este caso, con una cocinera de un club asturiano que cuenta lo que más le impactó en los años que lleva trabajando allí.

“... yo al principio sufría mucho... [...] pero luego poco a poco te vas habituando, te vas adaptando a eso pero... [...] mira, siempre, siempre, siempre lo cuento y me acuerdo una chica brasileña que le pregunté ¿a qué edad empezaste, mi vida, con esto? y dice... dice: empecé en mi país, y digo: ¿a qué edad, mi vida? dice: a los trece años y digo: ¡qué dices! dice: si, me prostituía en la calle y dice porque a los once, un vecino detrás del contenedor, me daba un bocadillo de pan, un bocadillo de chocolate pero si quería el bocadillo me tenía que dejar detrás del contenedor hacer el am.. el acto sexual con él, iyo me quedé boba! y después... y a qué te dedicabas? y decía: nada, por la calle, de vagabunda... jimagínate! una niña... y cosas así.. ¡buahhh!". [CS7: Cocinera de 50 años en un club]

La extrema vulnerabilidad de partida continúa para muchas mujeres venidas de situaciones de grave feminización de la pobreza que disfraza la supuesta libre elección de la prostitución en un mercado neoliberal en donde existen pocas oportunidades o alternativas (Miguel, 2015). Este continuum sitúa también a todas las mujeres en un proceso de asimilación y adaptación al ciclo de la violencia prostitucional a través de sus diversos contextos: trata sexual explotación sexual - prostitución (bien propios y/o de otras). Esta asimilación pasa por establecer falsos límites y distinciones para que cale en la preescripción social patriarcal de lo que se entiende por condición femenina. 


\section{REFLEXIONES FINALES}

La prostitución es una construcción simbólica y social que ha coincidido históricamente con los intereses políticos y económicos de la ideología hegemónica. El empleo de la violencia física es circunstancial (trata sexual) y gradualmente gestionado (explotación-prostitución) por el sistema prostitucional: productor de violencia simbólica contra todas las mujeres (legitimando la otredad femenina). En ella los varones socializados en el modelo de masculinidad tradicional hegemónica despliegan su necesidad de reafirmar su identidad a través de la cobertura sexual que se les proporciona. En las narraciones de las vivencias, prácticas sociales y discursos (lo que viven, hacen y cómo lo dicen) se pone de manifiesto esta forma de entender "ser hombre" y "ser mujer". Este orden sociosexual se caracteriza por una relación desigualitaria que se ejerce gracias a la disociación con la realidad que la acompaña: unos, para poder desarrollar una virilidad a través de una compulsiva vida sexual que se legitima con el grupo de pares; otras, para sobrevivir en un contexto opresivo en el que las condiciones de explotación abusivas preestablecidas desdibujan las distintas situaciones por las que transita una mujer: trata-explotación-prostitución.

En la investigación realizada de la comparativa del conjunto de los grupos/sistemas analizados se ha constatado que los imaginarios sociales de la prostitución y de la trata sexual configuran varios planos en los que se manifiestan diversas transferencias de invisibilidad: la más importante es que actualmente la trata sexual parece constituirse como un mecanismo de ocultacion de la prostitución. El corpus social mediante el sistema jurídico hipervisibiliza normativamente la trata sexual: es la única práctica penada pero apenas es identificada y esto la cuestiona constantemente pero gracias a ello (a ser nombrada y esteriotipada) exorciza cualquier responsabilidad no asumida con su continuum (explotación sexual-prostitución), que es tolerada. Asimismo, a través del sistema de género, la figura de la puta es asimilada con la prostitución y con ello se transfiere otra invisibilidad necesaria: la del clienteputero, legitimándose la institución dentro de una estructura social en comunión con el patriarcado y el neoliberalismo. En otro plano de la realidad prostibularia, la expresión lingüística de la prostitución también se invisibiliza con el lenguaje del mercado convertida en trabajo sexual, mucho más acorde 
con la ideología hegemónica patriarcal, y con ello se transfiere nuevamente la responsabilidad de la victimización sexual hacia las propias mujeres. Todos estos conceptos y contextos son construcciones que orientan la acción de los miembros de una sociedad y por lo tanto están designando además de un tipo de relaciones, unas expectativas sociales. Algo que es tomado como real sobre una situación o fenómeno y los imaginarios sociales se revelan como una herramienta idónea para su deconstrucción.

\section{REFERENCIAS}

Alecrín, Pérez Freire, S. y Carracedo Bullido, R. (2006). Informe Prostitución Lugo. Lugo: Ayuntamiento de Lugo.

Bourdieu, P. (2000). La Dominación Masculina. Barcelona: Anagrama.

Casado-Neira, D. y Pérez Freire, S. (2015). Sexo, masculinidades y víctimas expiatorias.

Las mujeres en contexto de prostitución en los medios: la mirada desde las Ong. Revista Internacional de Comunicación y Desarrollo, 2, 25-40. DOI: http:/ /dx.doi.org/10.15304/ricd.1.2.2468

Castoriadis, C. (1983-1989). La institución imaginaria de la sociedad. Barcelona: Tusquets.

CIS (Centro de investigaciones sociológicas). (2009). Encuesta nacional de salud sexual. Madrid: CIS.

Cobo Bedia, R. (2014). Informe proyecto de investigación: consentimiento y coacción. Prostitución y políticas públicas 2010-2014. Madrid: Instituto de la Mujer.

Cobo Bedia, R. (2017). La prostitución en el corazón del capitalismo. Madrid: Catarata. Connell, R.W. (2003). Masculinidades. México: Universidad Autónoma de México.

Chodorow, Nancy J. (1989). Feminism and Psychoanalytic Theory. Cambridge: Polity Press and New Haven, Yale University Press.

Jeffreys, S. (2011). La industria de la vagina. La economía política de la comercialización global del sexo. Buenos Aires: Paidós.

García Massagué, M. (2009). Historia de los burdeles. Barcelona: Editorial Oceáno.

Gimeno, B. (2012). La prostitución. Barcelona: Bellaterra.

Gimeno, B. (2015). Feminicidio por prostitución: el feminicidio invisible. Feminicidio.

De la categoría político-jurídica a la justicia universal (pp. 89-122). Madrid: Cátedra.

Goldberg, S. (1976). La inevitabilidad del patriarcado. Madrid: Alianza Editorial.

Gómez Suárez, Á. y Pérez Freire, S. (2009). Prostitución, clientes e outros homes. Vigo:

Edicións Xerais. 
Gómez Suárez, Á. y Pérez Freire, S. (2013). Informe técnico. Consumo de prostitución en España, clientes y mujeres (inédito). Madrid: Instituto de la Mujer.

Gómez Suárez, Á.; Pérez Freire, S. Verdugo Matés, R. (2015). El putero español. Madrid: Cátedra.

Gilligan, Carol (1982). In a different voice. Harvard: University Press.

Gilmore, David D. (1990). Manhood in the Making: Cultural Concepts of Masculinity. New Haven: Yale University Press.

Jeness, V. (1993). Making it work: the prostitutes'rights movement in perspective. Nueva York: Aldine de Gruyter.

Lamas, M. (2000). Diferencias de sexo, género y diferencia sexual. Cuicuilco, 7 (18). Recuperado de: http://www.redalyc.org/articulo.oa?id=35101807.

Lim, L.L. (1998). The sex sector: the economic and social bases of prostitution in Southeast Asia. Ginebra: Organización Internacional del Trabajo.

Luhmann, N. (1998). Sistemas sociales. Lineamientos para una teoría general. Barcelona: Anthropos.

Luhmann, N. (2006). Sociología del riesgo. México: Universidad Iberoamericana.

Michel, F. (2006). Planéte sexe. París: Homnisphères.

Millet, K. (2010). Política sexual. Madrid: Cátedra.

Moore, Robert y Douglas Gillette (1993). The Magician Within: Accessing the Shaman in the Male Psyche. New York: William Morrow \& Company.

Parsons, Talcott (1999). El sistema social. Madrid: Alianza.

Pateman, C. (1995). El contrato sexual. Barcelona: Anthropos.

OHCHR (Oficina del Alto comisionado de las Naciones Unidas para los derechos Humanos). (2002). La Abolición de la esclavitud y sus formas contemporáneas. Nueva York, Ginebra: Naciones Unidas.

Ortnert, Sherry (1979). Es la mujer al hombre lo que la naturaleza a la cultura?. EN O. Harris y K. Young (comps.). Antropología y feminismo. Madrid: Anagrama.

Harris, O. y Young, K. (1979) (comps.). Antropología y feminismo. Madrid: Anagrama. Miguel Álvarez, A. (2015). Neoliberalismo sexual. El mito de la libre elección. Madrid: Ediciones Cátedra.

NU (Naciones Unidas). (1950). Convenio para la represión de la trata de personas y la explotación de la prostitución ajena (96/1342). Bruselas: Naciones Unidas.

NU (1979). Convención sobre la eliminación de todas las formas de discriminación contra la mujer 34/180, de 18 de diciembre. Bruselas: Naciones Unidas.

NU (2004). Convención de las Naciones Unidas contra la Delincuencia organizada transnacional y sus protocolos. Nueva York: Naciones Unidas. 
Otegui Pascual, R. (1999). La construcción social de las masculinidades. Política y Sociedad, 32, 151-160.

Pérez Freire, S. (2013). Estudo exploratorio da trata de persoas en Galicia. Bruselas, Santiago de Compostela: International Center for Migration Policy Development (ICPMD), Xunta de Galicia.

Pintos de Cea-Naharro, J.L. (2003). El metacódigo relevancia-opacidad en la construcción sistémica de las realidades. Revista de investigaciones políticas y sociólogicas, 2 (2), 21-34.

Pintos de Cea-Naharro, J.L. (2014). Algunas precisiones sobre el concepto de imaginarios sociales. Revista Latina de Sociología, 4, 1-11. DOI: http:/ / dx.doi.org/10.17979/relaso.2014.4.1.1217

Thomas,W.I. (1928). The child in america: Behavior problems and programs. Nueva York: Knopf.

Ranea Triviño, B. (2016). Analizando la demanda: relación entre masculinidad hegemónica y prostitución femenina. Revista de Investigaciones feministas, 7 (2), 313-330. DOI: http:/ /dx.doi.org/10.5209/rev_INFE.2016.v7.n1.50746

Ropero Carrasco, J. y Ruiloba Alvariño, J. (2012). Explotación sexual y prostitución. Paradojas e hipocresías que impiden la protección de las víctimas. Revista de los investigadores del instituto de investigaciones jurídicas, 25, 87-109.

Sassen, S. (2003). Contrageografías de la globalización. Género y ciudadanía en los circuitos transfronterizos. Madrid: Traficantes de Sueños.

Segato, R. L. (2016). La guerra contra las mujeres. Madrid: Traficantes de Sueños.

Sullivan, M. (2007). Making sex work: the failed experiment of legalized prostitution in Australia. Melbourne: Spinifex. 